\title{
Research and Practice of Comprehensive Utilization Technology of Mine Water Based on Green Mining
}

\author{
Li Wang ${ }^{1,2}$; Yongzhi Fu³ ${ }^{3}$ Jingyan $\mathrm{Zhu}^{4}$ \\ ${ }^{1}$ Hulunbuir University, Hulunbuir 021008, Inner Mongolia; \\ ${ }^{2}$ Engineering Research Center for Safe Mining and Comprehensive Utilization of Mineral Resources in Universities of Inner Mongolia \\ Autonomous Region, Hulunbuir 021008, Inner Mongolia; \\ ${ }^{3}$ Dayan Mining Group Co., Ltd., Hulunbeier 021008, Inner Mongolia; \\ ${ }^{4}$ Sixth Geological Mineral Exploration of Inner Mongolia Development Co., Ltd., Hulunbuir, Inner Mongolia 021008
}

\begin{abstract}
Yannan Coal Mine in Dayan Mining Area creatively utilizes water-preserving mining technology to block abandoned roadways to build underground reservoirs and build underground sedimentation tanks. It implements a zoned utilization and zoned management optimization technical plan for mine water, so that it can meet the needs of underground working face production and surface production and domestic water use. This mine water comprehensively recycles water conservation mining technology and makes full use of mine water resources. This greatly improves the utilization rate of mine water, realizes the recycling of mine water, and accelerates the construction of green mines.
\end{abstract}

\section{INTRODUCTION}

With the increasing scale of coal mining in China, the ecological and environmental problems caused by coal mining have become increasingly prominent. For this reason, Qian Minggao, Academician of China University of Mining and Technology, proposed green mining technology to protect the ecological environment, of which water-preserving mining is an important branch of coal mine green mining technology. The goal of water-preserving mining is to protect the water resources within the mining area through relevant technical measures during coal mining, and to rationally utilize the mine water produced in the production mine. In this way, the disturbance to the hydrological environment of the mining area during the coal mining process is less than the capacity of the regional hydrological environment. At present, many mining areas have carried out water conservation mining research and technical practice, and have achieved remarkable results. For one thing, these research results have carried out research from limiting mining height, leaving coal and rock pillars, and changing coal mining methods. In this way, the water-conducting channel will not penetrate the aquifer, so as to reduce the loss of water resources and realize the purpose of water-preserving mining, and the water-preserving mining can be carried out from the purification and recycling technology of underground drainage. Dayan mining area has also done a lot of work in water conservation mining. For another, Yannan coal mine in the mining area creatively blocked underground exhaust gas roadways to build underground reservoirs and build sedimentation tanks, and used mine water for production and life underground and above the mine. In this way, the recycling of mine water is realized, which plays a positive role in protecting the ecological environment of the mining area and promotes the construction of green mines.

\section{General Situation of Hydrogeology in YANNAN CoAl Mine}

Yannan Coal Mine in Dayan Mining Area is located in Hulunbuir City. The topography of its mine field is relatively simple, mostly low and gentle grassland hills. It has a semi-arid continental climate, and the surface water system of the mine fields is dominated by rivers. In the north of the mining area, the Hailar River flows from east to west, and the river bed is $58-130 \mathrm{~m}$ wide. It is an old-age river. These rivers have a large curvature rate, and are widely distributed along the oxbow lakes and floodplains on both sides of the river. The maximum peak flow rate is $1057 \mathrm{~m}^{3} / \mathrm{s}$, and the average flow rate for many years is $66 \mathrm{~m}^{3} / \mathrm{s}$. The river is $1 \mathrm{~km}$ away from the nearest point of the mining area and is separated by hills, which has little impact on mine development. At the same time, there are seasonal rivers Shengligou Creek and Buluomoyegou Creek flowing from east to west in the mining area. It dries up in winter, and the flow is slightly larger during summer floods.

There is no major river in Dayan Coalfield, and Yannan Coal Mine is located in the west of Dayan Coalfield. The aquifers in the minefield are mainly Quaternary aquifers, coal-measure weathered zone fractured pore aquifers, coal-measure formation sandstone pore aquifers and coal volcanic weathered fracture zone aquifers. The mine aquifer is more complex, and the 
weathered cracks of the coal seam are rich in water, which is hydraulically connected with the impact aquifer and surface water. Through the analysis of mine water influx in different periods and locations, it is found that the main sources of mine groundwater replenishment are precipitation replenishment, water conduction through faults and aquifer infiltration replenishment. The average annual water inflow of the mine is 2.5404 million $\mathrm{m}^{3}$.

\section{Current Status of Mine Water UTILIZATION}

The original mine water utilization method is mainly to drain and discharge, using the draining equipment to discharge the mine water from different locations to the underground central sump. Afterwards, it will be discharged to the ground mine water treatment workshop for simple sedimentation and purification, dust reduction in the ash plant, greening of the site and grouting station. Tap water is used for underground production and surface production, domestic and fire fighting water. The annual recycling consumption is only $32,100 \mathrm{~m}^{3}$, the mine water recycling rate is low, and the water treatment cost is high. Due to direct emissions, not only a large amount of water resources is wasted, but also the surrounding ecological environment is polluted. At present, Yannan Mine uses abandoned roadways to build underground reservoirs, optimizes mine water utilization plans, and significantly improves mine water utilization. In this way, the recycling utilization of mine water is realized and the pace of green mine construction is promoted.

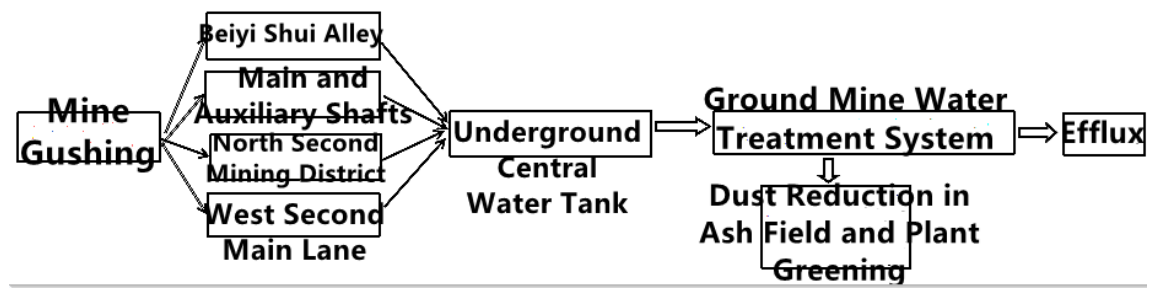

Figure 1. Schematic Diagram of the Original Mine Water Utilization Process

\section{TeChNical Scheme for Optimization of Mine Water Utilization}

In Yannan Mine, due to the complex water replenishment path of mine water, the water points of mine water are mainly concentrated in the North No. 1 air shaft, the No. 2 mining area, the No. 2 main road and the main and auxiliary shafts. Due to the scattered water gushing locations, the original centralized drainage method has high cost, low utilization rate and complex management system. Therefore, we use partition management technology based on the occurrence of each water point. We will use the North No. 2 mining area and the main and auxiliary shaft gushing water to maintain the original mine water utilization system, the West No. 2 main lane design sedimentation tank, and the North No. 1 discharge lane plugging the optimized technical plan for the construction of underground reservoirs. In this way, the mine water can be recycled and the utilization rate of the mine water can be improved.

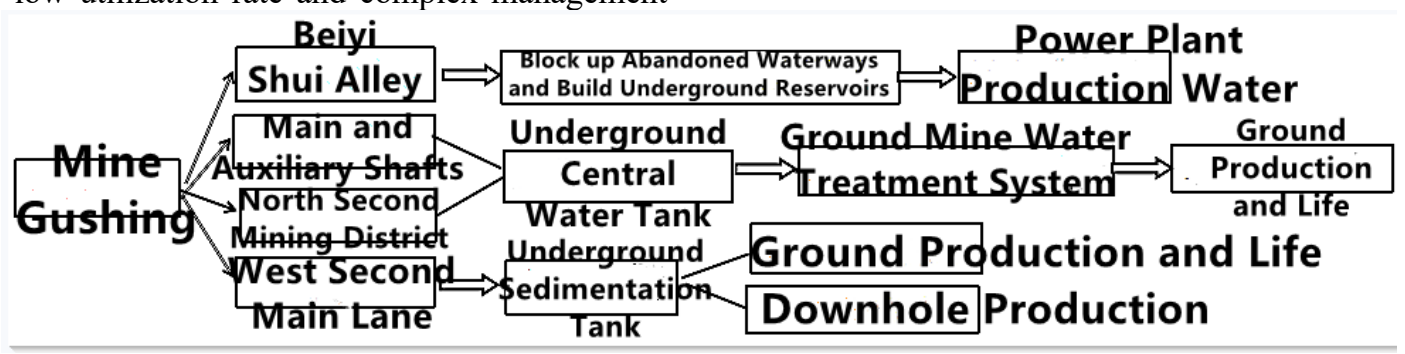

Figure 2. Schematic Diagram of Optimization Scheme for Mine Water Recycling in Yannan Mine

\subsection{Water Conservation Mining Technology for Underground Reservoir in Abandoned Roadway}

The main water gushing location in the Bei No. 1 mining area is located in the Bei No. 1 air shaft, and there are three main water outlets in the well. The elevation of the first water outlet is $+644.0 \mathrm{~m}$, the vertical distance from the wellhead is $28.5 \mathrm{~m}$, the lithology is gravel, and the thickness is $4.95 \mathrm{~m}$. The elevation of the second water outlet is $+629.5 \mathrm{~m}$, the vertical distance from the wellhead is $43 \mathrm{~m}$, the lithology is gravel, and the thickness is $5.2 \mathrm{~m}$. The elevation of the third water outlet point is $541.8 \mathrm{~m}$, the water inflow is about $5-10 \mathrm{~m}^{3} / \mathrm{h}$, and the vertical distance from the wellhead is $130.7 \mathrm{~m}$. The elevation of the static water level in the shaft of the North No. 1 wind shaft is $+645.90 \mathrm{~m}$, and the water inflow at the first and second locations is about $80 \mathrm{~m}^{3} / \mathrm{h}$. The working staff set up a retaining wall at the bottom of the roadway at an elevation of $612 \mathrm{~m}, 150 \mathrm{~m}$ from the wellhead, and a height difference of $34 \mathrm{~m}$ from the static water level. They chose a section with small roadway deformation and intact support, and closed the roadway $50 \mathrm{~m}$ above the retaining wall. In this way, the water inflow in the air shaft can achieve water pressure balance after the water inflow point exceeds the water inflow point, and the water inflow level will no 
longer rise, so that the abandoned roadway will eventually form an underground reservoir. At the same time, the staff will use the explosion-proof submersible pump in the reservoir to transport the Beiyi gushing water to the circulating water pump room of the Yannan Thermal
Power Plant as supplementary water for the thermal power plant.

The third water outlet point has a small amount of water gushing. The gushing water can enter the Beiyi drainage lane through the No. 1 borehole, and finally flow into the main sump of the mine through the ditch.

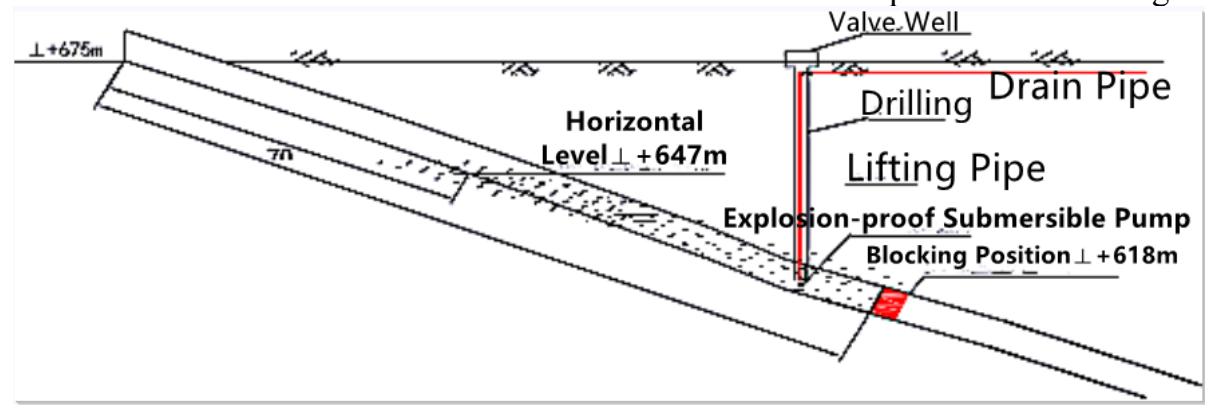

Figure 3. Blocking Abandoned Roadways and Building Underground Reservoirs for Water Conservation and Mining

\subsection{Mine Water Recycling Technology in Xi'er Daxiang}

The water inflow of West Second Main Lane is $120 \mathrm{~m}^{3} / \mathrm{h}$, and the water volume is stable. In combination with the water quality of the West Second Gushing Water, the designer uses part of the West Second Main Lane Gushing Water for underground production and dust suppression, and part of it is raised to the ground as the main water source for industrial site production, toilet flushing, and fire fighting. Therefore, the staff will construct a sedimentation tank in the connecting lane of the West Second Railway Station. The sedimentation tank has a project volume of $30 \mathrm{~m}$ and a capacity of $125 \mathrm{~m}^{3}$. The gushing water from the West Second Well enters the sedimentation tank through the water ditch, and is used by the underground water sites and the ground after sedimentation and filtration.

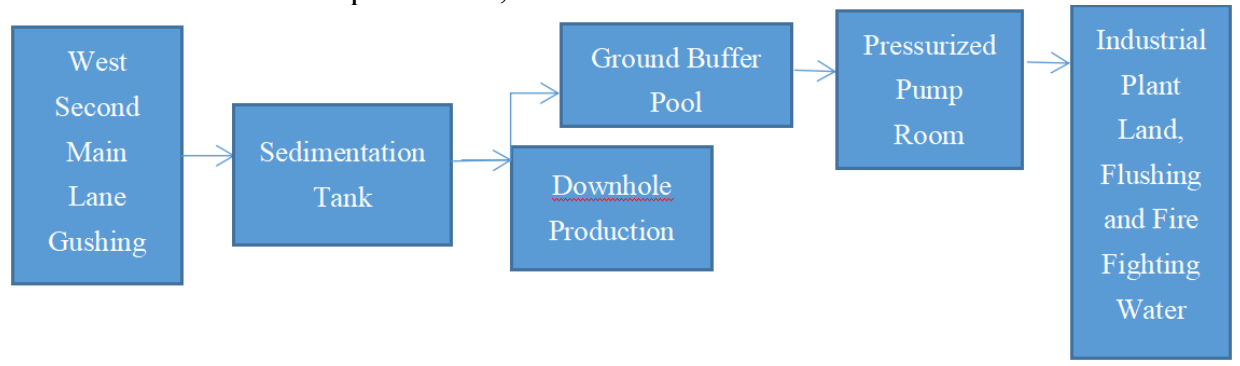

Figure 4. Flow Chart of the Utilization Process of West Second Gushing Water

\section{Application Effect Analysis}

\subsection{Water Quality Test Results}

Researchers found through water quality inspection (Table 1) that the clean water quality after sedimentation

\begin{tabular}{lccl}
\hline \multicolumn{1}{c}{ Test Items } & Test Result & Standard & $\begin{array}{l}\text { Individual } \\
\text { Evaluation }\end{array}$ \\
\hline Total Coliform & 2 & $<3$ & Qualified \\
Total Number of Colonies & 8 & $\leq 100$ & Qualified \\
PH Value & 7.98 & $6 \sim 9$ & Qualified \\
Total Hardness ${ }^{*}$ & 227 & 450 & Qualified \\
Chloride $^{*}$ & 7 & 250 & Qualified \\
Total Dissolved Solids $^{*}$ & 214 & 1000 & Qualified \\
Sulfate & 110 & $\leq 250$ & Qualified \\
Free Residual Chlorine & 0.1 & $\leq 4$ & Qualified \\
Turbidity & $\leq 0.5$ & \multicolumn{3}{c}{$\leq 5$} & Qualified \\
\hline & \multicolumn{3}{c}{ Note: $*$ The detection is the mass concentration, the unit is mg/L. }
\end{tabular}




\subsection{Technical and Economic Effect Analysis}

After the implementation of the project, the annual tap water consumption has been reduced from the original 1.370 million $\mathrm{m}^{3}$ to $182,000 \mathrm{~m}^{3}$, which can save 1.188 million $\mathrm{m}^{3}$ of tap water and 2.970 million yuan in taxes and fees. The amount of mine water reuse increased from the original $32,100 \mathrm{~m}^{3}$ to 1.2201 million $\mathrm{m}^{3}$. Among them, $371,400 \mathrm{~m}^{3}$ was reused underground, $816,600 \mathrm{~m}^{3}$ was reused on the ground, and the mine water recycling rate was increased from $1.26 \%$ to $48 \%$. The annual mine water reuse tax rate does not decrease but increases by 1.6332 million yuan. The external discharge of mine water gushing has been reduced from 2,110,100 $\mathrm{m} 3$ to $1,622,100 \mathrm{~m}^{3}$. It can reduce the discharge of mine water outflow by 1.188 million $\mathrm{m}^{3}$ every year, and save 5.94 million yuan in taxes and fees for the discharge of mine water.

\subsection{Reduce Mine Water Treatment Costs}

Since the gushing water from West 2 and North 1 can be directly reused without treatment, the amount of water entering the mine water treatment workshop from the central sump is greatly reduced. This not only reduces the pressure on the processing workshop, but also reduces the processing cost accordingly. The water heating company estimates that it can save 358,000 yuan in water treatment costs each year. In the meantime, after optimizing the utilization of mine water, the power consumption of each link is also reduced accordingly, which can save 184,000 yuan in electricity costs each year.

\subsection{Environmental and Social Benefits}

The further utilization of mine water resources, the reuse of mine water as underground raw water and industrial site production, domestic, and fire-fighting water reduces the amount of groundwater extracted. This can not only realize the comprehensive utilization of mine water resources, but also greatly reduce the pollution of surface water and groundwater from mine drainage. This not only protects and saves water resources, but also effectively improves the comprehensive utilization rate of water resources in mining areas. Its environmental and social benefits are very obvious.

\section{CONCLUSION}

All in all, Yannan Coal Mine optimized the mine water recycling plan, creatively plugged abandoned roadways and built underground reservoirs and built sedimentation tanks underground for production of underground working face and ground production and daily use. This not only reduces the direct discharge of mine water, but also realizes the recycling of mine water, which plays a positive role in protecting the ecological environment of the mining area. Simultaneously, this also reduces the pressure on the surface water treatment plant, saves water treatment costs, and brings economic benefits to the enterprise. Furthermore, this has also played a demonstrative role in the water conservation mining technology of coal mines in the Hulunbuir area, and has accelerated the construction of green mines in the Hulunbuir coal mine.

\section{ACKNOWLEDGMENT}

Hulunbuir University of Inner Mongolia Autonomous Region serves the local key project "Research on the Construction of Coal Mine Green Mines in Hulunbeier Area Based on Comprehensive Utilization" (2019FDZD01).

\section{REFERENCES}

1. Qian Minggao, Xu Jialin, Miao Xiexing. Coal mine green mining technology $[\mathrm{J}]$. Journal of China University of Mining and Technology, 2003, 32 (4):

2. Wu Qiang, Shen Jianjun, Wang Yang. "Coal-water" dual-resource mining technology method and engineering application[J].Journal of China Coal Society,2017,42(1):8-16.

3. Gu Dazhao. Theoretical framework and technical system of coal mine underground reservoirs [J] Journal of China Coal Society, 2015, 40 (2): 239-246.

4. Wang Yu, Wang Dapeng, Huo Bingjie. Practice of water conservation mining technology in coal mine area [J]. Coal Mining. 2010, 15 (1): 44-46.

5. Chen Sushe, Ju Jinfeng. Daliuta Coal Mine Water Resources Utilization Technology [J]. Coal Science and Technology. 2011, 39 (2): 125-128.

6. Pang Yihui, Li Peng, Zhou Baojing. Technical feasibility study of underground reservoir construction in coal mine with $8.0 \mathrm{~m}$ large mining height [J]. Coal Engineering. 2018, 50 (2): 6-15.

7. Cao Qingyi, Ren Wenying, Chen Siyao, etc. Coal mine water treatment technology and utilization status [J]. 2020, 42 (3): 1-5.

8. Li Xiangnan. Research on the status quo and improvement strategies of coal mine water treatment[J]. Comprehensive Utilization of Resources in China. 2019.37(3): 51-53.

9. Liu Zhong. Discussion on the current situation and development of coal mine water conservation mining technology $[\mathrm{J}]$. Resource Information and Engineering. 2016.31 (6): 70-74. 